\title{
A Review on Agency Cost in China
}

\author{
Ming Shao, Yaxin Wang \\ School of Economics and Management, Huazhong Agricultural University, Wuhan, China \\ Email: 18202732829@163.com
}

How to cite this paper: Shao, M. and Wang, Y.X. (2018) A Review on Agency Cost in China. Open Journal of Business and Management, 6, 225-233. https://doi.org/10.4236/ojbm.2018.62016

Received: January 18, 2018

Accepted: March 31, 2018

Published: April 3, 2018

Copyright (c) 2018 by authors and Scientific Research Publishing Inc. This work is licensed under the Creative Commons Attribution International License (CC BY 4.0).

http://creativecommons.org/licenses/by/4.0/

\begin{abstract}
Under the modern corporate system, one of the basic problems of corporate governance is to reduce the agency cost, but it is under the influence of the company's internal governance structure and external environment. Since agency cost problems in corporate governance have been a research hot spot, this paper teases out a profile of relevant research achievements of agency costs from 2012 to 2017 in China, and summarizes the influence factors and the economic consequences relating to agency cost in the form of literature review. After some discussion and argument, this paper analyses the trend of the existing research and puts forward the future research prospects in this field that is spillover effect of agency costs at the macro micro level.
\end{abstract}

\section{Keywords}

Corporate Governance, Agency Theory, Agency Cost, Chinese Studies

\section{Introduction}

Modern companies are the integration of team power with a number of living individuals, including managers, employees, shareholders, creditors, and so on. For a long time, economists chronically assume and think that these parties have a common goal and orientation, but actually there is a conflict of interests among economic individuals. And companies have been trying to reconcile these contradictions. Therefore, it has always been the focus of scholars in the field of corporate finance and capital markets.

Over the past three decades, economists have worked hard and developed the so-called "agent theory". In Principles of Corporate Finance by Richard A. Brealey and Stewart C. Myers, it is listed as one of the seven most important concepts in corporate finance [1]. Strictly speaking, agency theory is one of the inter disciplinary research achievements in economics and finance. It is the emergence of agency theory that drives us to make a breakthrough in the study of the internal 
structure of the black box of enterprises.

With detailed data, Adolf Berle and Gardiner Means (1932) observed the separation of control and ownership in the United States in the 1920s and 1930s, and pioneered the study of corporate governance [2]. Jensenand Meckling (1976) defined the agency cost and discussed the agency problem in Theory of firm: managerial behavior, agency costs and ownership structure [3]. The agency cost seems to be the inevitable product of modern stock company (Harold Demsetz, 1988) [4]. Since then, most researches on corporate governance issues started through agency costs, and tried to find ways to reduce agency costs and alleviate agency problems, which is one of the basic objectives of corporate governance.

China, as the world's second largest economy, has a profound impact on the international capital market as China's stock market and bond markets open up to the outside world. With the clear opening direction of China's capital market and more considerations from future international investors, corporate governance and agency efficiency of listed companies in China are worthy of attention due to its subject status. At the same time, along with the rapid development of domestic capital market in recent five years, the interests of capital market participants are becoming more and more sharp, and the external supervision of China's listed companies are lagging behind, which leads to the frequent harassment of corporate governance problems in China's listed companies.

In the most recent case, take Vanke as an example. As the first listed company to survive and the country's leading real estate company, the competition for equity between Vanke management and outside shareholders raises new questions about the principal-agent relationship between the executive team and the shareholders. How to alleviate the problem of agency has become one of the important topics that listed companies have to pay attention to.

In the past five years, domestic scholars have also made a lot of research on this area and made some achievements. They try to find a good way to reduce agency costs and ease the agency problems in China with a unique economy in transition. Thus this paper attempts to focus on the recent research of agency cost in the last five years, summarizes the impact factors and economic consequences involved in the literature in the form of literature review, and summarizes the current research trends. The future research prospect of this field is put forward.

\section{Agency Cost}

\subsection{Definition}

According to Jensen and Meckling (1986), the principal needs to pay the price for preventing agents from damaging their own interests, for instance, they take actions to restrict agents' behaviors through strict contractual relationships and strict supervision on agents. It is the price the principal has to pay that the agency costs [5]. Agency costs include delegated monitoring costs, the guarantee cost 
of the agent and residual loss.

The supervision cost of the client refers to the incentive and monitoring cost of the principal to make the agent do everything possible to pursue maximum benefit of the principal; The guarantee cost of the agent means the cost that the agent guarantees not to damage the interests of the principal, and vice versa the cost of compensation. As for the residual loss, it signifies the loss of value arising from the decision of the principal on behalf of the agent. Assuming that the agent and the client share the same information and talents, the residual loss is equal to the difference between the two parties' decision-making.

\subsection{Measurement}

Asset turnover ratio, operating expense ratio and management shareholding ratio are the frequently used indicators to measure the agency problem between shareholders and management. Asset turnover is very intensively effective in measuring the company's investment decisions and the assets turnover management, while operating expense rates focus on measuring overconsumption of the management and other agency costs (Ang, 2000, Singh \& Davidson, 2003) [6] [7]. Luo Wei and Zhu Chunyan (2010) contend that it is feasible to measure the agency cost between shareholders and management by the proportion of managerial ownership [8].

For the proxy problems between shareholders and creditors, Mello and Parsons (1992) demonstrate the incentive effect of capital structure by using undetermined equity model and measure the agency cost of creditor's rights [9]. Prowse (1992) blazed a new trail to scale such agency costs by using ratio of cash and tradable securities to total assets [10]. McKnight and Weir (2009) measure the total agency cost by the ratio of sales income to total assets and the number of mergers and acquisitions, and propose that agency cost is a function of free cash flow and growth opportunity [11].

In general, agency cost can be summed up as the cost of principal relationship. As mentioned above, it can be divided into three types in accordance with the signing and execution process. From the perspective of static analysis, scholars focus on share holders and management, shareholders and creditors. Most of the existing studies indirectly measure the agency cost and seldom directly measure it. It can be seen that it is difficult to quantify directly agency costs, which poses the severe requirement of exploring new methods for empirical research.

\section{Influencing Factors of Agency Cost in the Past Five Years' Research}

The existence of agency cost directly leads to the reduction of corporate value. How to effectively supervise and encourage the business operators to ensure the efficient operation of the company and the goal of maximizing the interests of the owners and reduce agency cost effectively is a subject that has attracted much attention since the agency problem was raised. There are many factors af- 
fecting agency cost, which mainly concentrate on the information asymmetry, interest inconsistency, incentive incompatibility, free-rider behavior and uncertainty. Considering the feasibility of research and design, Chinese scholars focus on institutional factors, including formal institution and informal institution, which are divided into external supervision, cultural factors and individual factors.

On external supervision, formal system perspective is mostly based on the legal environment and media supervision (Ye Yong et al. 2013) [12]. Zeng Jianguang's and others innovative research probe into the impact of Internet governance on the agency costs of Chinese Listed Companies in China [13]. To some extent, the legal environment, media supervision and Internet governance reduce the asymmetric degree of information in the principal-agent problem, improve the transparency of information, and thus reduce the agency cost and improve agency efficiency.

Cultural factors include religious traditions, cultural practices, social trust, regional languages and social relations. The long-term accumulated religious traditions, cultural customs and other informal institutions in a region have gradually caught domestic scholars' eyes. By studying the relationship between religious tradition and corporate governance, Chen Donghua (2013) found that there is less illegal behavior of the listed companies and the lower cost of earnings management in the place with stronger religious tradition [14], That is, the informal system helps to improve the quality of corporate governance. Based on the data of listed companies in Shanghai and Shenzhen stock exchange from 2002 to 2012, Gu Zhihui (2015) studied the relationship among Confucian ethics, globalization and agency cost [15]. As one of the important components of the informal system, social trust's role of corporate governance is also worth exploring When studying CEO power and agency cost, Li Xiaoling (2016) takes into consideration the regulatory role played by the trust environment, thus proving that the trust environment can restrain the influence of CEO power on agency cost to some extent [16].

Most of the above studies measure culture macroscopically. With the development of sociological research, the culture of language or dialect representation can be refined to financial individuals, which makes it feasible to solve how to measure culture at individual level and identify the influence of culture on individual decision-making. Based on this, Dai Yi-yi (2016) empirically tests the influence of dialect consistency between president and CEO on agency cost, and finds that dialect consistency can significantly reduce agency cost and the narrower the range of use of a dialect is, the more significant this effect is [17].

Liu Xiaoxia et al. (2013) divided the relationship between the actual controller and the general manager into three categories according to the degree of intimacy: the first type is the relatives of blood, kinship or marriage; The second kind is the acquaintance from the same country, class or colleague; If the above relations are not, they can be classified into the outsiders [18]. Through empiri- 
cal methods, those papers demonstrate the influence of the "relationship" on agency cost and agency efficiency. In view of the highly valued personal reputation in Chinese society, Luo Jinhui (2014) categorized independent directors into star directors and ordinary directors in terms of the social reputation mechanism of independent directors [19]. Furthermore, they analyze the difference of governance effect between two kinds of independent directors in alleviating the agency problem of listed companies.

From the above analysis, we can draw the conclusion that the research on the anatomy of the unique cultural phenomenon in China and its effect on corporate governance enrich and supplement the micro-study of culture and finance, and provide a new empirical basis for the market stakeholders to know the vital role of Chinese cultural traditions in regulating economic development.

Besides, from the perspective of organizational behavior, some scholars analyze how the demographic characteristics of clients and trustees and their social networks exert influence on the agency cost. The following demographic variables of team members are a matter of great concern, such as age, duration of service, educational level, race, gender, etc. The similarities between executives' backgrounds, such as common experiences, hometown, educational background and even political tendencies, can also affect the relationship between the two parties and thus affect agency costs in corporate governance (Lin Yun-jian, 2016; Huang Ya-wei, 2016; Lu Dong et al., 2012 \& 2014) [20] [21] [22] [23].

\section{Economic Consequences of Agency Costs}

The early research on the economic consequences of agency cost started from the macroscopic and macroscopic levels respectively. The former includes capital structure and financing activities, while the latter involves business cycle, economic fluctuation and growth (Dang Yin, 2012) [24]. For a change, the characteristics of the relevant literature in the last five years have shown that domestic scholars pay more attention to the economic consequences of the micro level.

With a view to market microstructure, Xiong Jiacai (2016) used stochastic frontier model to study the impact of stock liquidity on management agency cost of Chinese listed companies, and found that the value of China's listed companies was reduced by about $33.6 \%-37.8 \%$ due to agency conflicts [25]. Similar to Shao Shuai's (2015) research, agency cost between the large and small shareholders gained a slight decrease in those listed companies owned by actual controllers, thus the value of the company showed an improvement [26]. Within the framework of Upper echelons theory and agency theory, Wanpeng and Quxiaohui (2012) reveal the influence of personal characteristics and agency cost on the voluntary disclosure of corporate income plan [27]. Tan Weijia and Huang Songqin (2017) made an empirical study on the motivation of corporate donation from different perspectives, and came to the same conclusion that the cost of agency has a positive correlation with the scale of corporate donation, which 
also indicates the principal-agent problem in corporate philanthropy [28].

With regard to the relationship between agency cost and company performance, there is no unanimous conclusion up to now. Yao Guoxuan and $\mathrm{Wu}$ Qiong (2014) analyze the relationship between equity incentive, agency cost and corporate performance in China's financial insurance industry and their results show a negative correlation between agency cost and firm performance [29].

Aiming at the double principal agent problem and using the panel data of China listed company, Chen Wenqiang (2015) constructed the intermediary effect model of "equity incentive-agency cost-enterprise performance", empirically test how equity incentive affects enterprise performance and agency cost, and how the agency cost acts on the relationship between equity incentive and enterprise performance [30]. The results show that equity incentive has a significant effect on corporate performance, and it is effective to restrain the first kind of agency cost, nevertheless, the governance effect on the second kind of agency problem is not significant. The first kind of agency cost plays an intermediary role between equity incentive and enterprise performance, to put it another way, equity incentive restrains the first kind of agency cost, and then indirectly promotes the enterprise performance with no sign of mediating effect of second one.

\section{Research Prospects and Conclusions}

Most of the researches are based on the rational human hypothesis and ignore managers' heterogeneity and behavioral preferences, notwithstanding the in-depth institutional research and intensive analysis on influencing factors of agency cost. The importance of the managers' social attributes has led to the release of rational man hypothesis and focus on managers' behavioral preferences in the whole social and cultural context. At the same time, with the rapid development of sociology and psychology, many measures and methods that can represent the characteristics of social human behavior have been excavated step by step, which to a large extent solves the problem that variables are difficult to quantify in empirical research. From my perspective, the interaction between the managers' personal characteristics and the company's stakeholders is a proposition that deserves further study.

Studies on the individual characteristics of executives by Foreign Scholars are rich and interesting with detailed and full-fledged theory. Because the domestic senior executive individual information and data is not mandatory disclosure, there is less research on the individual characteristics of corporate decision-making and corporate agency behavior. I think we can further study the individual characteristics of senior executives, not only age, education, professional background and so on, but also the cultural factors that appear on the executive individual, the experience at all stages of life, personal risk preference.

As for the agency cost of economic consequences, most concerns are related to governance issues at the company level in that the basic goal of corporate go- 
vernance is to relieve the principal-agent problem and improve the efficiency of principal agent, especially in China setting with the imperfect system. For the state-owned listed companies in China, there is a double or multiple agency relationship, so it is far from enough to simply apply or imitate the existing achievements of foreign agency theory. We also must combine our country's special national condition to give the concrete analysis. In my eyes, the study of governance efficiency at the micro level can be improved and deepened. Meanwhile, our research should take into consideration the social impact of enterprises and social roles with the wide vision and more interdisciplinary research. At the corporate level, we can consider the influence of agency cost on the communication of information within the organization, especially financial information.

It can be seen from the above review that the scholars' conclusions on the influence of some factors on agency cost are not the same. The research on the factors of agency cost is relatively rich at present, and the factors mostly root in the informal system. The empirical method of multivariate regression is widely used in the study. Owing to plentiful factors and greater interaction, there are few comprehensive analysis and classification of these factors, which often lead to the omission or repetition of some characteristic factors, which may affect the universal applicability of the conclusions. So by combing the research results of agency cost in China from 2012 to 2017, this paper summarizes the influencing factors and economic consequences and induces the current research trends, subsequently with the future research prospect of this field.

\section{References}

[1] Brealey, R.A. and Myers, S.C. (2008) Principles of Corporate Finance. McGraw-Hill Publishing Ltd., New York.

[2] Berle, A. and Means, G. (1991) The Modern Corporation and Private Property. Transaction Publishers, Piscataway.

[3] Jensen, M.C. and Meckling, W.H. (1976) Theory of the Firm: Managerial Behavior, Agency Costs and Ownership Structure. Journal of Financial Economics, 3, 305-360. https://doi.org/10.1016/0304-405X(76)90026-X

[4] Demsetz, H. (1988) The Organization of Economic Activity, 2 Vols. Blackwell, Hoboken.

[5] Jensen, M.C. (1986) Agency Costs of Free Cash Flow, Corporate Finance, and Takeovers. The American Economic Review, 76, 323-329.

[6] Ang, J.S., Cole, R.A. and Lin, J.W. (2000) Agency Cost and Ownership Structure. Journal of Finance, 55, 81-106. https://doi.org/10.1111/0022-1082.00201

[7] Singh, M. and Davidson III, W.N., (2003) Agency Costs, Ownership Structure and Corporate Governance Mechanisms. Journal of Banking \& Finance, 27, 793-816. https://doi.org/10.1016/S0378-4266(01)00260-6

[8] Luo, W. and Zhu, C.Y. (2010) Agency Cost and Voluntary Disclosure. Economic Research, 10, 143-155.

[9] Mello, A.S. and Parsons, J.E. (1992) Measuring the Agency Cost of Debt. Journal of Finance, 47, 1887-1904. https://doi.org/10.1111/j.1540-6261.1992.tb04687.x

[10] Prowse, S.D. (1990) Institutional Investment Patterns and Corporate Financial Be- 
havior in the United States and Japan. Journal of Financial Economics, 27, 43-66. https://doi.org/10.1016/0304-405X(90)90020-Z

[11] McKnight, P.J. and Weir, C. (2009) Agency Costs, Corporate Governance Mechanisms and Ownership Structurein Large UK Publicly Quoted Companies: A Panel Data Analysis. The Quarterly Review of Economics and Finance, 49, 139-158. https://doi.org/10.1016/j.qref.2007.09.008

[12] Ye, Y., Li, M. and Huang, L. (2013) Legal Environment, Media Supervision and Agency Cost. Guides to the Securities Market, 9, 47-53.

[13] Zeng, L.G. and Wang, L.Y. (2015) Internet Governance and Proxy Generation-Evidence Based on Google's Big Data. Economic Science, 1, 112-125.

[14] Chen, D.H., Hu, X.L., Liang, S.K. and Xin, F. (2013) Religious Tradition and Corporate Governance. Economic Research Journal, 59, 71-84.

[15] Gu, Z.H. (2015) Confucian Ethics and Agency Cost in the Context of Globalization. Management World, 3, 113-123.

[16] Li, X.L. and Fang, S.Y. (2016) A Study on the Relationship between CEO Power and Agency Cost in Different Trust Environments. Journal of Anhui University (Philosophy and Social Sciences Edition), 4, 145-156.

[17] Dai, Y.Y., Xiao, J.L. and Pan, Y. (2016) Can "Xiang Yin” Reduce the Agency Cost of the Company? A Study Based on Dialect. Economic Research, 51, 147-160.

[18] Liu, X.X. and Rao, Y.L. (2013) The Influence of "Relationship" on Agency Cost and Agency Efficiency of Private Listed Companies. Systems Engineering, 11, 40-47.

[19] Luo, J.H. and Huang, Z. (2014) Is the Star Independent Director a Vase? From the Perspective of Double Agency Cost. Journal of Shanxi University of Finance and Economics, 1, 76-90.

[20] Lin, Y.-J. and Ji, S.-M. (2016) Executive Background Characteristics, Agency Cost and Charitable Donation. Friends of Accountancy, 4, 59-62.

[21] Huang, Y.-W. (2016) A Study on the Influence of Executive Background and Earnings Management on the Senior Executives Salary in Private Enterprises. Jilin University, Changchun.

[22] Lu, D., Yu, L. and Lin, G. (2014) Executive's Administrative Background, Dual Costs and Company Performance-Empirical Evidence from State-Owned Listed Companies. Financial Science, 3, 39-50.

[23] Lu, D., Lin, G., Huang, L. and Yang, D. (2012) Official Executives, Firm Performance and Unproductive Expenditure-Empirical Evidence Based on State-Owned Listed Companies. Financial Research, 6, 139-153.

[24] Dang, Y. (2011) A Summary of the Research on the Agent Cost in the Corporate Governance. Journal of Zhongnan University of Economics and Law, 4, 1-8.

[25] Xiong, J.C. and Su, D.W. (2016) Stock Liquidity and Agency Cost: An Empirical Study Based on Stochastic Frontier Model. Nankai Management Review, 1, 84-96.

[26] Shao, S. and Lu, C.J. (2015) Can Direct Shareholding by Actual Controllers Enhance the Value of the Company? Evidence from Private Listed Companies in China. Management World, 5, 134-188.

[27] Wan, P. and Qu, X.H. (2012) Chairman's Personal Characteristics, Agency Costs and Voluntary Disclosure of Revenue Plans-Empirical Evidence from Shanghai and Shenzhen Listed Companies. Accounting Research, 7, 15-23.

[28] Huang, S.Q. (2017) The Agency Cost, the Changes of Institutional Environment and Corporate Philanthropy from China Manufacturing Industry Empirical Evi- 
dence. Journal of Shanghai University of Finance and Economics, 1, 75-87.

[29] Yao, G. and Wu, Q. (2014) Research on the Relationship between Agency Cost and Corporate Performance. Statistics and Decision-Making, 24, 174-176.

[30] Chen, W.Q. and Jia, S.H. (2015) Equity Incentive, Agency Cost and Enterprise Performance-An Analysis Framework Based on Double Principal-Agent Problem. Contemporary Economic Science, 3, 106-128. 